\title{
The Reuse of Waste Electrical and Electronic Equipment (WEEE). A Bibliometric Analysis
}

\section{Dolores Queiruga ${ }^{1}$ and Araceli Queiruga-Dios ${ }^{2}$}

${ }^{1}$ Department of Economics and Business Administration, University of La Rioja, Edificio Quintiliano. C/ La Cigüeña 60. 26006 Logroño, Spain, E-mail: dolores.queiruga@unirioja.es

${ }^{2}$ Department of Applied Mathematics, ETSII. University of Salamanca, Avda. Fernandez Ballesteros 2, 37700-Bejar, Salamanca, Spain, E-mail: queirugadios@usal.es

*Corresponding author: Dolores Queiruga, Department of Economics and Business Administration, University of La Rioja, Edificio Quintiliano. C/ La Cigüeña 60. 26006 Logroño, Spain, E-mail: dolores.queiruga@unirioja.es

Received date: April 17, 2015, Accepted date: May 28, 2015, Published date: June 03, 2015

Copyright: () 2015 Queiruga D,et al. This is an open-access article distributed under the terms of the Creative Commons Attribution License, which permits unrestricted use, distribution, and reproduction in any medium, provided the original author and source are credited.

\section{Abstract}

The management of Waste Electrical and Electronic Equipment (WEEE) has much scope for improvement in almost all countries. Some legislation, such as the European Directive, aims to increase reuse, to prevent such equipment from being recycled without being reused. In this sense, the reuse of WEEE has a huge interest from an economic, environmental, legal, and social viewpoint. However, this has not been studied much so far. This paper adopts a bibliometric analysis of the scholarly literature that has addressed the study of reuse of WEEE. For the purpose, we have examined 32 papers on this topic, indexed up to 2014 in the Scopus database, and have identified trends and opportunities related to the what, how, and where of the research in this matter.

The results show the need for further investigations on certain aspects of reuse in order to overcome the barriers that exist in different countries. In particular, further case studies are needed in countries that practice greater reuse. Further research is also necessary in logistics and the reasons why different economic agents do not reuse WEEE. Besides, it is also important to understand the aspects of strategic human resource management and operation management of reuse centers.

Keywords: Waste; Electronic equipment; Reuse; Bibliometric

\section{Introduction}

In recent years, there has been a growing concern about waste electrical and electronic equipment (WEEE) management and this is reflected in many academic case studies that elucidate how their management is or could be in different countries, such as the United States [1], China [2], Japan [3], Switzerland [4,5], United Kingdom [6], Germany [7], or Spain [8].

One of the possibilities for managing electrical and electronic equipment at the end of their lifecycle is their reuse. The European WEEE Directive 2002/96/EC presented a hierarchy of actions for the management of WEEE that reuse should assume priority over recycling. According to this legislation, reuse, recycling, and recovery targets have to be met for 10 different categories of electrical and electronic equipment by EU member countries. However, the Directive did not specify separately the percentage of recycling and reuse. In fact, the need for reuse was hardly mentioned. The minimum requirements included in the legislation suggested only recycling, and rarely, reuse [9]. Therefore, the result of the application of this Directive was that member countries installed only the necessary infrastructure for recycling (e.g. in Germany [9] or in Spain [10]). In practice, the WEEE management system operates in such a way that the countries mainly recycle; and the reuse is rare and only by just a few social stakeholders [11-13].

In some countries, such as Spain, much of the WEEE collected (approximately 70\%) goes to unauthorized and uncontrolled players to be treated outside the official channels provided for this purpose, i.e.
$[8,14]$, the waste does not reach its rightful destination, which is an authorized WEEE treatment plant, but are irregularly or illegally "lost." It is unknown where exactly this waste ends.

Paradoxically, this situation is not inconsistent with the fulfillment of the 2003 Directive. This means that this situation could be maintained because the law required only recycling of a certain amount (4 kg per inhabitant per year). Nevertheless, it is expected that not so many equipment would get lost with the new legislation in place, because the required amount to be reused and recycled depends on the number of the equipment placed on the market.

In 2012, the new Directive 2012/19/EU came into force and it was incorporated into the national legislation in 2014. Until December 31, 2015, the collection of $4 \mathrm{~kg}$ per inhabitant per year of WEEE from private households will still be required [15]. However, from 2016, the minimum collection rate that is to be achieved is $45 \%$ of the average weight of electrical and electronic equipment (EEE) placed on the market by each member state in the three preceding years. From 2019, a choice between two options is possible: either $65 \%$ of the average weight of EEE placed on the market, or $85 \%$ of WEEE generated by the member state. This implies that the requirements for recycling and reuse are no longer measured as a fixed amount depending on the number of inhabitants, but are related to the amount of products placed on the market. This new Directive emphasizes the preparation of WEEE for reuse [9]. As suggested by the new legislation, the amount of WEEE to be treated is increasing, so more equipment must enter the waste management system. In Spain, at present, there are some reuse plants near shutdown because they do not receive enough equipment. For example, the company Ekorrepara is near bankrupt because it is receiving insufficient equipment passing through its 
system. In the past, the Integrated Management Systems (IMS) used to provide the equipment, but now, they have opted for a recycling plant [16]. Paradoxically, the demand for second-hand EEE is exceeding the supply [17].

There is an ongoing debate about the benefits of reuse. Some authors argue that even intensive product reuse of EEE reduces total resource consumption of a highly developed industrial economy by less than $1 \%$ [18]. Some authors argue that recycling is not always profitable [19]. But for many others, reuse may involve several environmental and socioeconomic benefits [20], such as extending the useful life of equipment, protecting the environment, or facilitating access of the unemployed to jobs [18], and also facilitating the acquisition of equipment by people with few resources. However, the technological, economic, social, and environmental structure of the reuse chain is largely unknown [21]. Furthermore, reuse is necessary to facilitate compliance with the European Directive.

In the scientific literature, the management of WEEE for recycling has been widely studied from both a logistical and a technological point of view. However, there are considerably less studies on reuse. It is important to know what has been done and what remains to be done in a field with different opinions. It is still unknown how reuse may be cost-effective and beneficial to the environment and society in a way in which recycling can be cost-effective and beneficial to the environment and society. In addition reuse plants need to improve their management and relations with other economic and social actors in order to get more equipment to repair, and thereby, improve their results. Again, from a legislative point of view, reuse should be increased. Due to this research need, the objective that had been suggested was to make a review of the literature addressing what, how, and where reuse has been researched so far, allowing us to discover what remains to be learnt in the field of WEEE reuse. To achieve this, we will address three key issues: (1) what is being researched, i.e., what specific waste management activities have been studies from what perspectives and what products category; (2) how to research, i.e., what research methodologies are used; and (3) where has it been investigated, i.e., which geographical areas has the work been carried out in and in which journals are the articles disseminated? To obtain the necessary information, we adopted a bibliometric standpoint to analyze the scholarly literature that addresses the study of WEEE reuse.

To do this, we analyzed the academic papers included in the Scopus research database. The main interest of this article, as with the majority of bibliometric studies, is that it allows the research conducted so far to be assessed, while, at the same time, helping to identify current weaknesses and future opportunities. Moreover, reviews and studies of this nature help prospective researchers to situate and contextualize their contributions to the field of study in question [22-25].

The paper is organized into 6 sections. Section 2 describes the methodology used in the study. Section 3, 4 and 5 focuses on elucidating the what, how, and where, respectively, of the research into WEEE reuse. Section 6 summarizes the main conclusions, while singling out some of the study limitations, which, in turn, pose certain challenges for future research.

\section{Methodology}

To conduct a systematic review of the literature, we followed following steps: identify the field of study and period of analysis; select information sources; and search, manage, and debug the results and analyze them [26]. This study has centered on the scholarly contributions published up to 2014 and indexed in the Scopus database. The Scopus interdisciplinary database indexes more than 14,000 peer-reviewed publications. The use of a multidisciplinary database was positive for our review because the reuse topic can be explained from a number of different perspectives [27], such as business, technical, environmental, or social. We noted beforehand that some of the more representative journals in the field of management and environment (e.g., Resources, Conservation \& Recycling, Waste Management, and Journal of Cleaner Production) were indexed in the database. We, therefore, concluded that the Scopus database would provide a reasonably accurate view of the research carried out.

A search was, therefore, conducted using two keywords: "reuse" and "WEEE," whereby we called up all those contributions that mentioned both the terms in any one of the registered fields in the database (title, keywords, abstract, authors' details, etc.). The only other restriction was that the articles must have been published in scholarly journals through a peer-review process. In June 2014, these criteria resulted in overall 66 papers. Regarding the subsequent work of classifying and ordering, each of these papers was read and analyzed by at least two researchers independently, with the intervention of a third in case of difference in opinions.

Largely owing to the use of such open search criteria, the process of analysis and classification also involved a screening of the initial sample-with 34 papers being discarded because although they contained the keywords, the subject area was out of purview of the study. This is explained by the fact that, for example, some of the words appeared only in the authors' registration details; they received only a cursory mention in the text speaking about the legislation targets. Some other papers used the WEEE legislation as an example pertaining to another sector, as in the case of cars or packaging reuse. There are some published studies related to reuse as secondary raw materials. The final number of papers considered in this research, therefore, was 32 (see annex 1). It is a smaller number of papers than in other bibliometric reviews because it is a current topic with not much available literature.

\section{What is Being Researched?}

\section{Scope of research}

According to the European Directive, reuse is defined as "any operation by which WEEE or components thereof are used for the same purpose for which they were conceived, including the continued use of the equipment or components thereof which are returned to collection points, distributors, recyclers or manufacturers" (Art. 3, d, WEEE Directive). Reuse is one of the possibilities of WEEE management. Therefore, for this bibliometric review, we describe the context of the reuse as part of WEEE management. Considering the whole system from production to waste management, we have classified the papers according to the chosen approach, i.e., according to the volume of items and activities considered during the analysis.

Thus, we can distinguish from the papers that take a broad approach and consider reuse as one option among others to those that focus exclusively on reuse. To group the papers, depending on the scope, we suggest four possibilities: (1) Direct and reverse logistics; (2) 
Page 3 of 8

Collection, reuse, recycle, disposal; (3) Reuse, recycle, disposal; and (4) Reuse.

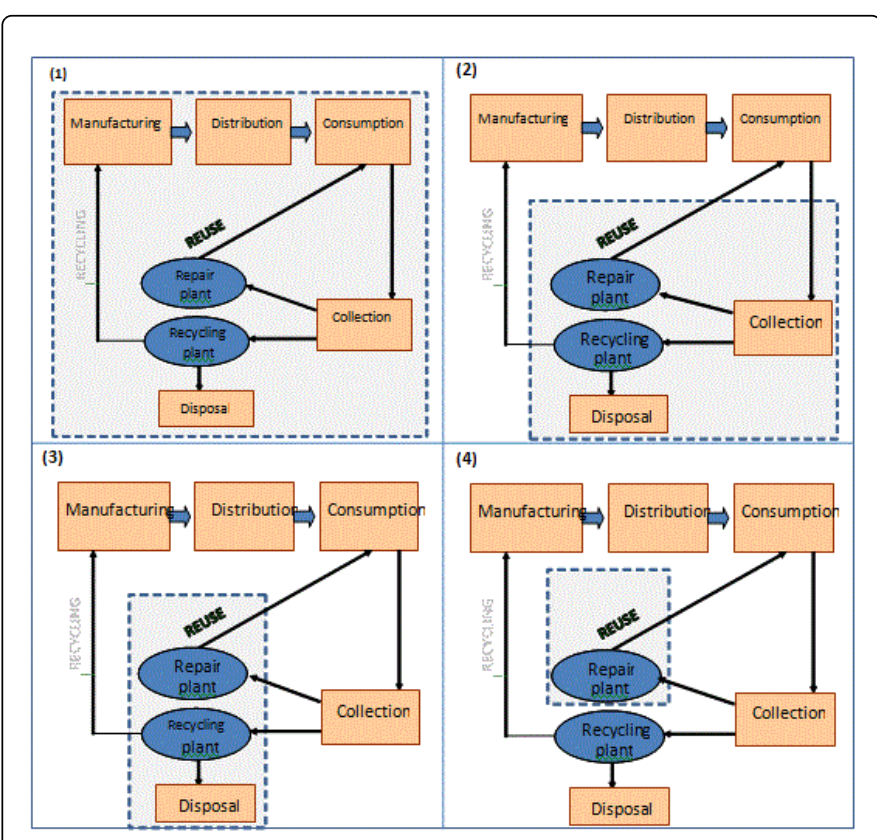

Figure 1: Four possibilities to study the management of WEEE, if reuse is included.

Some of the papers involved in this review analyze the management of WEEE in general; others focus on specific activities such as collection, reuse, recycling, and disposal. However, most of the documents focus on two activities: reuse and recycling. These are the two WEEE management alternatives after use; therefore, most of the studies are centered on these two key options. These papers are too general to take into account the whole supply chain, and are not so specific as to consider only reuse; and they focus on what the possibilities are with the devices.

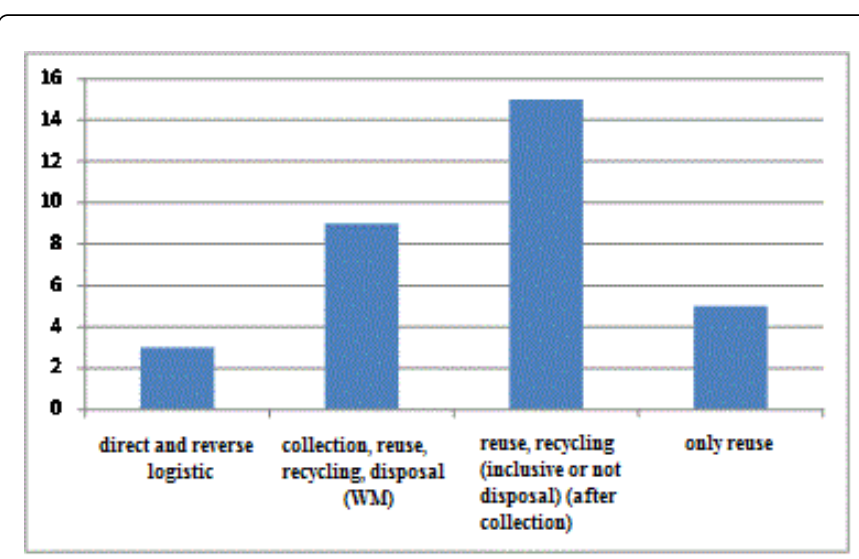

Figure 2: Distribution of papers by scope of research.

Figure 2 shows the number of items for each possibility of research. When interpreting this graph, it must be remembered that these are not articles on the management of WEEE in general, but only those that include reuse.
This means that there are many papers not listed here that include both, the direct and reverse logistics. For this reason, the fact that there are few items in the first category, "direct and reverse logistics" does not mean it is a topic that needs further research, but that articles on the topic of reuse are realized in the context of reverse logistics.

It is remarkable that the first research on this topic, including reuse, appears in 2002 [28]; however, if we look for the words "WEEE management" in the same database (Scopus), we find papers dating back to 1998. It has also been drawn our attention that only four papers refer exclusively to reuse and these are concentrated mainly between 2012 and 2014. This indicates that reuse, as an option to reduce waste, has not received much attention on its own, but does so only as an option linked to recycling. With the whole research activity centered around logistics and case studies, solutions can be given in terms of economic, social, and environmental terms. At the same time, countries can learn from the case studies from other countries and could provide recommendations to others. It would, therefore, be useful to lay more emphasis on research that is exclusively on reuse.

\section{Organizational focus}

It is also important to know if the papers take an inter- or intraorganizational focus, that is, if they focus on issues related to logistics, transportation, or products storage, or, if instead, they address technological topics, operations, or decisions in plants. Figure 3 groups the papers under each approach.

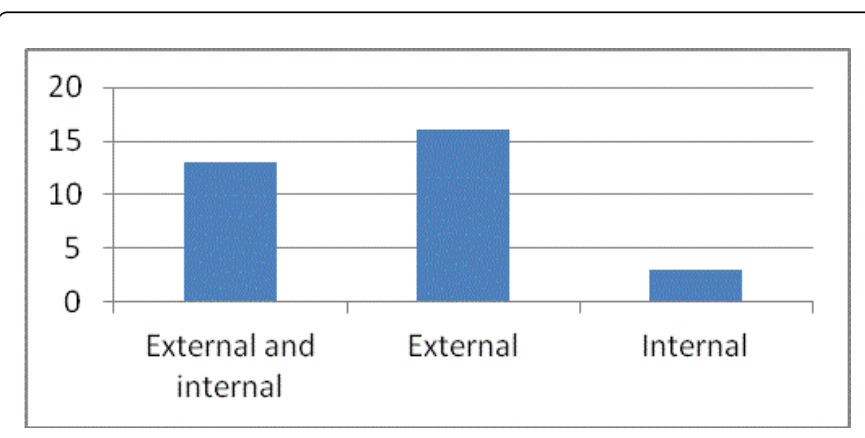

Figure 3: Distribution of papers by organizational focus.

The results show that there is little research exclusively carried out inside the plants. This disparity could be understood by the fact that reparation has always been carried out in most sectors, and therefore, does not require such an immediate technology development. In this sense, it would not be necessary to increase research on reuse plants technology.

However, it is important to consider that other aspects and decisions of reuse plants, such as strategic management, marketing, or human resources management, are not addressed in any paper. These topics have been extensively studied in factories, but not in recycling or reuse plants, which have some issues that differ from factories (these were analyzed, for example, by Rogers et al. [29]).

As Kissling et al. $[30,31]$ state, the lack of products to repair and to put back on the market is a barrier for reuse. In addition, different stakeholders involved in the management, such as manufacturers or recyclers, also pose barriers.

Therefore, more knowledge and research in these areas would be important to overcome the barriers, for example, about the proper use 
Page 4 of 8

of resources and capacities of reuse plants. Another possible area of research is the management of importing used products. Yet another possibility would be analyzing the implications of establishing new agreements with the stakeholders involved. However, reuse plants have traditionally acted within local markets and such decisions may be difficult for them.

\section{Product category}

To define the product categories, we used the 10 categories proposed by the European Directive as the most known and used in scientific papers. At the same time, this division includes all types of devices: (1) Large household appliances; (2) Small household appliances; (3) Information and Communication Technologies; (ICT); (4) Consumer equipment; (5) Lighting equipment; (6) Electrical and electronic tools; (7) Toys, leisure, and sports equipment; (8) Medical devices; (9) Monitoring and control instruments; and (10) Automatic dispensers.

The results show that most of the articles address the management of WEEE from a general perspective (see Figure 4). This is because the law is the same for all devices, and therefore, the design of logistics systems that might be used by everyone should be proposed. However, some devices have specific characteristics, such as PCs or mobile phones, which are replaced more than others. Large appliances also have distinctive characteristics because of their size, and so also refrigerators, due to the special treatment of the toxic substances that they contain.

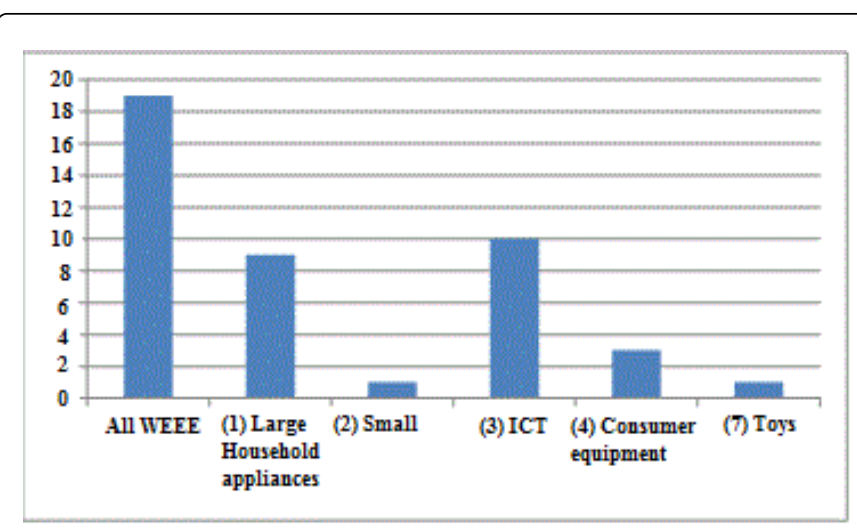

Figure 4: Distribution of papers by product category.

There is certainly very little research in categories such as toysonly one paper. Toys, like other household appliances, are sometimes unusable, but in other cases, they are discarded while they are still in working conditions. When this happens, it would be important to conduct further research to improve the resale market within our own country or in foreign countries.

The other products and categories, such as lighting equipment, electrical and electronic tools, medical devices, monitoring and control instruments, automatic dispensers, for which there is no article, are basically very specific non-domestic use equipment pertaining to a specific profession. It can be expected that they will be replaced by modern technology when they stop working properly with the new ones. It would make sense to analyze the suitability of the export of these products to countries lagging behind in the technology. On the other hand, from the social point of view, investment in reuse plants would be beneficial to developing countries.

As for papers dealing exclusively with reuse, they are related to all WEEE in general, including ICT and large household appliances. Therefore, there is no difference from other papers with a wider scope.

\section{How Reuse is Investigated?}

\section{Methodological approaches}

As reuse can be studied from any branch of study, such as management, engineering, production management, sociology, or law, we have classified the papers into two major generic methods: theoretical and empirical. Under the theoretical method, we have included those dealing with the legislation status, waste management in a specific country, or a management model. The papers, which incorporate the development of mathematical models or conduct interviews with consumers or stakeholders, are included in the empirical category. Papers with a cost-benefit analysis with the amounts of discarded products and others with software development for information management are also included in the empirical section.

The results show that the number of items in each method is comparable (Figure 5): 13 theoretical work papers and 19 empirical. This highlights that it is not only necessary to develop mathematical models and calculate the most efficient logistics systems to properly manage waste, it is also important to be familiar with case studies about how other countries apply the law, the role of each stakeholder, and the relationships between them.

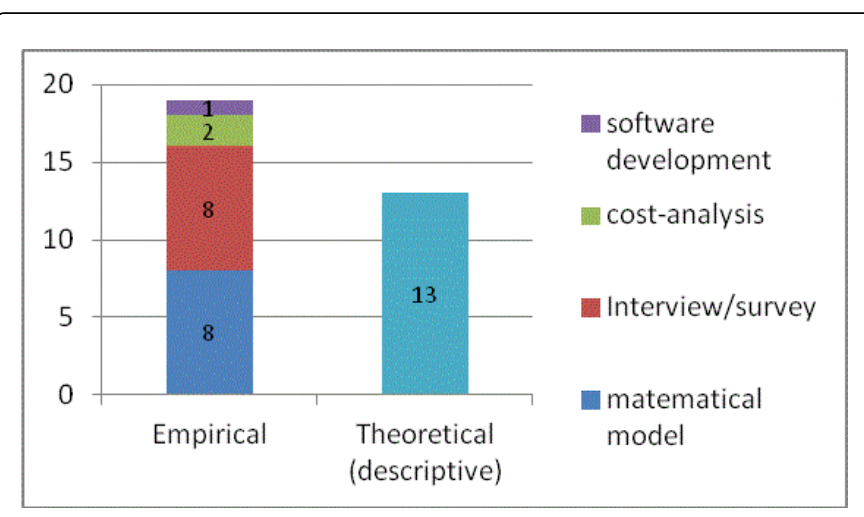

Figure 5: Distribution of papers by methodological approach.

Among the 19 empirical papers, 8 use mathematical models, 8 include interviews, 2 perform cost analysis, and the last one develops software. Regarding the overall waste management or WEEE recycling topics, some software applications have been developed to know the waste stream (e.g., Ofiraee is a Spanish virtual office that receives the request to collect the WEEE from collection points and notifies the Integrated Management Systems). It would be interesting to develop software tools to centralize information about the status of obsolete equipment, connecting the collection points with the reuse plants.

\section{Disciplinary perspective}

The subject of WEEE management, in general, and reuse, in particular, can be studied from different disciplines and different 
Page 5 of 8

points of views. On the one hand, if the equipment is reused, it takes longer to be a waste product, which affects the environment. On the other hand, it is a requirement of the legislation. Finally, it is necessary to know the role of the agents involved and to calculate the most suitable logistics and their costs. Due to the need to consider all these perspectives of reuse, we have distinguished four points of view: (1) economic, (2) social, (3) environmental, and (4) legislative.

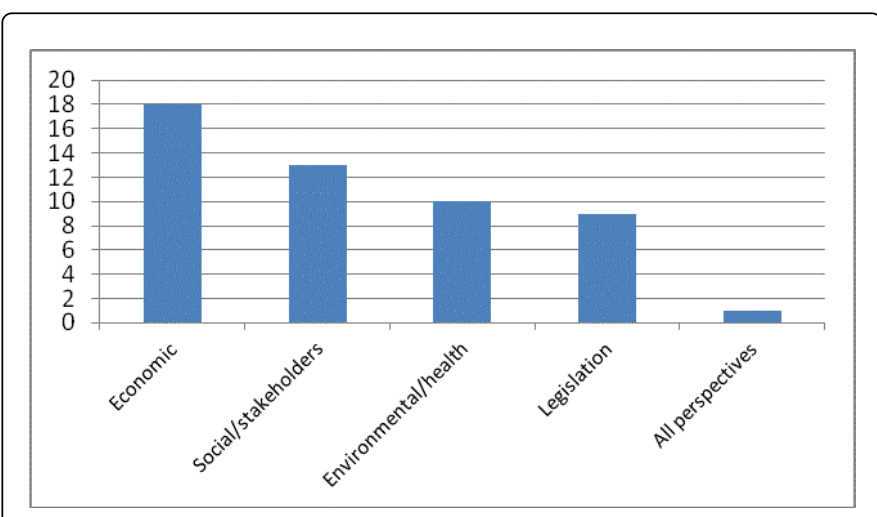

Figure 6: Number of papers for each perspective.

Even though the legislative perspective appears less frequently (Figure 6), we should always be aware that compliance with the legislation is an underlying factor in most of the literature on this topic. This is evidenced by the significant increase of scientific papers directly or indirectly arising from the entry into force of new legislations such as the European Directive.

Whatever the focus of the papers, the underlying issue is how best to manage waste. However, since the producer is financially responsible for waste management in many countries, it would be interesting to also investigate the management of waste from the point of view of strategic management or business management, and not just from the point of view of waste management.

\section{Where has it been Investigated?}

\section{Geographic scope of research}

The results obtained according to the geographical scope of research are presented in Figure 7.

Some papers analyze waste management in several countries. In such cases, we have added each country involved in the graph. What we wanted to know was which countries participate and which do not. Most of the papers under examination belong to Europe and Asia. Some of them are centered in specific cities, but others are about the whole country. There are some other papers from major geographical areas such as Latin America or North America. The reason why there is a lot of research in Europe may be because the European Directive requires some changes and the researchers want to know how they could bring about these changes. In the case of Asia, there is a problem with importing products and informal waste management systems. Researchers try to raise these relevant issues.

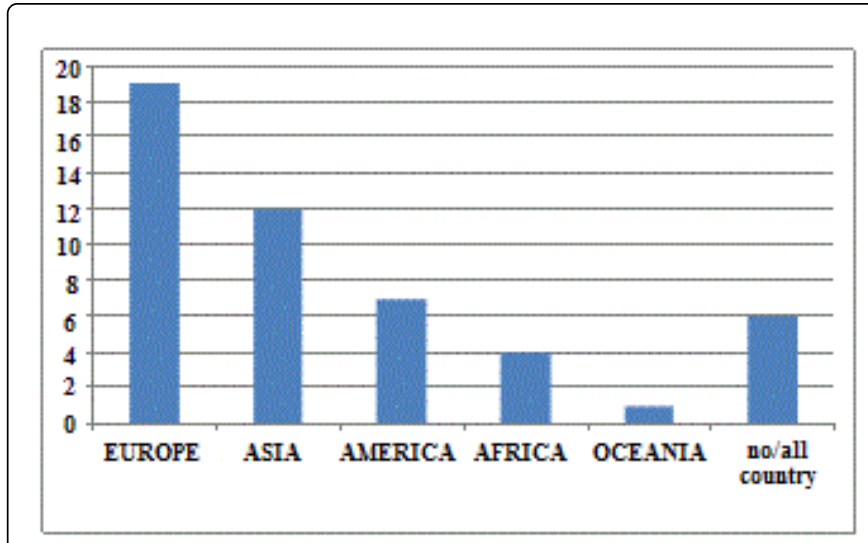

Figure 7: Distribution of papers by countries.

Of particular interest is the low number of papers dealing with North America and Africa, as in both continents, research about the increase of reuse would be extremely important: In the case of America, it is a country that traditionally exports WEEE to other countries. Instead of exporting, the environmental, social, and economic benefits could be analyzed, repairing WEEE and promoting the market for second-hand goods or even repairing and exporting. Africa could also consider equipment reuse.

\section{Journals where the articles are published}

Figure 8 shows the graph with a list of all the journals involved in this review.

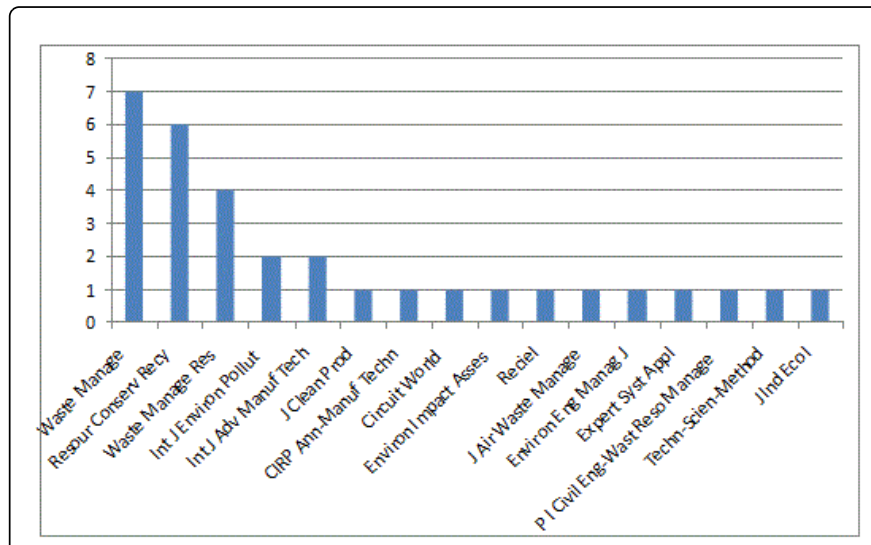

Figure 8: Distribution of papers by journal.

The reuse topic is researched from an environmental, engineering, or business point of view. This is reflected in the fact that most journals that publish articles on this subject are concerned about waste management and resource conservation: Waste Management (7 papers); Resources, Conservation and Recycling (6 papers); Waste Management and Research (4 papers). The remaining items are divided into one or two papers per journal (environment, technology, or industry journals).

Although it is true that reuse may favor the environment, and that logistics management and process improvements are needed, it is also true that other journals could research reuse in a multidisciplinary 
Page 6 of 8

way, such as with human resources or sociology, as there are social enterprises dedicated to reuse too. Strategic management journals could also contribute much to this topic.

\section{Conclusions}

After answering the questions what, how, and where, the work has highlighted, on the one hand, existing reuse barriers, and on the other, the need for further research. Therefore, for each barrier to reuse, we propose more intense research in the area. Some specific issues that we could not answer after our analysis are:

- Some studies analyze the barriers of reuse in different geographic areas (e.g., [31] in Africa, Latin America, North America, and Europe), but it is important to analyze it in each country through case studies. As numerous case studies on WEEE recycling have been published, reuse could also be likewise analyzed. Thus, some countries could learn from the experience of others to overcome their barriers. It is important to conduct these case studies in developing countries too, since they are the recipients of numerous obsolete equipment from other countries.

- The second research topic could help overcome the most important reuse barriers, i.e., the lack of access to sufficient volumes of equipment used for different reasons [30,31]. It is necessary to study the reasons from the point of view of consumers, retailers, and manufacturers. It is possible that new contracts between companies or government aid could improve this situation.

- According to the results of our analysis, the issue of reuse is treated mainly from a technical and environmental point of view. However, to enhance the number of equipment obtained from reuse plants, there are certain aspects of the plant's decisionmaking process that could be improved. Therefore, we conclude that further research is necessary from the point of view of business management, strategic management, and human resources.

- For WEEE recycling, logistics systems have been developed in all countries and there are new operators, such as virtual office registration to register the number of equipment or Integrated Management Systems. In the same way, it is important to research the same as related to reuse. Logistics costs are also a barrier to reuse $[30,31]$.

We can conclude that there are few studies on reuse and increasing the numbers could contribute to understanding how reuse is dealt in different countries and how to improve this activity. As a conclusion of the whole analysis, we can say that if reuse is not studied exclusively, there is a risk of considering it as a marginal activity.

This work is not without its limitations-which can lead to new research opportunities. We have used only one "database." It would be interesting to use other databases, which may slightly increase the number of items that can be considered.

\section{Acknowledgements}

This research was partially funded by the Spanish Government and FEDER funds through research project ECO2013-47280-R. Aid was also received from the research project SA083A12-1 financed by the Consejeria de Educacion de la Junta de Castilla y Leon (Regional Ministry of Education of Castile and Leon).

\section{References}

1. Kang HY, Schoenung JM (2005) Electronic waste recycling: A review of U.S. infrastructural and technology options. Resources, Conservation and Recycling 45: 368-400.

2. Veenstra A, Wang C, Fan WJ, Ru YH (2010) An analysis of E-waste flows in China. International Journal of Advanced Manufacturing Technology 47: 449-459.

3. Aizawa H, Yoshida H, Sakai S (2008) Current results and future perspectives for Japanese recycling of home electrical appliances. Resources, Conservation \& Recycling 52: 1399-1410.

4. Streicher-Porte M, Widmer R, Jain A, Bader HP, Scheidegger R, et al. (2005) Key drivers of the e-waste recycling system: Assessing and modelling e-waste processing in the informal sector in Delhi Environmental Impact Assessment Review 25: 472-491.

5. Hischier R, Wagner P, Gauglhofer J (2005) Does WEEE recycling make sense from an environmental perspective? The environmental impacts of Swiss take-back and recycling systems for waste electrical and electronic equipment (WEEE). Environmental Impact Assess Review 25: 525-539.

6. Turner M, Callaghan D (2007) UK to finally implement the WEEE Directive. Computer Law \& Security Report 23: 73-76.

7. Spengler T, Luger T, Herrmann C (2010) Implementation of the WEEEdirective. Economic effects and improvement potentials for reuse and recycling in Germany. International Journal of Advanced Manufacturing Technology 47: 461-474.

8. Queiruga D, González-Benito J, Lannelongue G (2012) Evolution of the electronic waste management system in Spain. Journal of Cleaner Production 24: 56-65.

9. European Parliament and Council (2012) Directive 2012/19/UE of the European Parliament and of the Council of 4 July 2012 on Waste Electrical and Electronic Equipment (WEEE), Brussels, Belgium.

10. Roller G, Führ M (2008) Individual Producer Responsibility: A Remaining Challenge under the WEEE Directive. Reciel 17: 277-283.

11. Huisman J, Magalini F, Kuehr R, Maurer C, Ogilvie S, et al. (2007) 2008 Review of Directive 2002/96 on Waste Electrical and Electronic Equipment (WEEE). Final report. United Nations University, Japan.

12. O'Connell M, Hickey S, Fitzpatrick C (2010) Investigating Reuse of B2C WEEE in Ireland. Proceedings of the IEEE International Symposium on Sustainable Systems \& Technology (ISSST), Washington, USA.

13. Gamberini R, Gebennini E, Rimini B (2009) An innovative container for WEEE collection and transport: Details and effects following the adoption. Waste Management 29: 2846-2858.

14. OCU-Compra Maestra (2012) Reparación ordenadores portátiles 371.

15. European Parliament and Council (2003) Directive 2002/96/EC of the European Parliament and of the Council of 27 January 2003 on Waste Electrical and Electronic Equipment (WEEE), Brussels, Belgium.

16. Alcántara M (2012) EkorreparaS.Coop. Centro para la Reutilización Red Social Koopera. Primeras Jornadas RELEC de preparación para la reutilización. Sevilla.

17. Rubio García L, Ramos Álvarez A, Atienza de Andrés M (2012) Preparación para la reutilización: experiencia en el tratamiento de RAEEs de las entidades recuperadoras de AERESS en el contexto de aprobación de la nueva Directiva 2012/19/EU. Congreso Nacional del medioambiente.

18. Truttmann N, Rechberger H (2006) Contribution to resource conservation by reuse of electrical and electronic household appliances. Resources, Conservation and Recycling 48: 249-262.

19. Barba-Gutierrez Y, Adenso-Díaz B, Hopp M (2008) An analysis of some environmental consequences of European electrical and electronic waste regulation. Resources, Conservation and Recycling 52: 481-495.

20. Rreuse (2012) Challenges to boosting reuse rates in Europe.

21. Baker S, King A (2007) Organising Reuse: Managing the Process of Design For Remanufacture (DFR). POMS 18th Annual Conference Dallas, Texas, USA. 
22. Qureshi AS, McCornick PG, Qadir M, Aslam Z (2008) Managing salinity and waterlogging in the Indus Basin of Pakistan. Agricultural Water Management 95: 1-10.

23. González-Benito J, Lannelongue G, Alfaro-Tanco JA (2013) Study of supply-chain management in the automotive industry: a bibliometric analysis. International Journal of Production Research 51: 3849-3863.

24. Li Si Y, Hao Chun B, Feng Chuan P, Wang Li H, Liu Y (2014) A bibliometric analysis on acidophilic microorganism in recent 30 years. International Journal of Waste Resources 4: 1-7.

25. Pérez-Belis V, Bovea MD, Ibáñez-Forés V (2015) An in-depth literatures review of the waste electrical and electronic equipment context: Trends and evolution. Waste Management \& Research 3: 3-29.

26. Medina-López C, Marín-García J, Alfalla-Luque R (2010) Una propuesta metodológica para la realización de búsquedas sistemáticas de bibliografía. Working Papers on Operations Management 1: 13-30.

27. Kissling R, Coughlan D, Fitzpatrick C, Boeni H, Luepschen C, et al. (2013) Success factors and barriers in re-use of electrical and electronic equipment. Resources, Conservation \& Recycling 80: 21-31.

28. Hume A, Grimes S, Boyce J (2002) Environmental product attributes in end-of-life management in the UK. Problems encountered with informational systems for the management of end-of-life IT and office equipment. International Journal of Environment and Pollution 18: 126-137.

29. Rogers DS, Tibben-Lembke RS (1998) Going Backwards: Reverse Logistics Trends and Practices. University of Nevada, Reno. Center for Logistics Management.

30. Kissling R (2011) Best Practices in Re-Use. Success Factors and Barriers for Re-use Operating Models. StEP (Solving the e-waste problem).

31. Kissling R, Coughlan D, Fitzpatrick C, Boeni H, Luepschen C, et al. (2013) Success factors and barriers in re-use of electrical and electronic equipment. Resources, Conservation \& Recycling 80: 21-31.

\section{Annex 1}

1. Manomaivibool P, Hong, JH (2014) Two decades, three WEEE systems: How far did EPR evolve in Korea's resource circulation policy?Resources, Conservation \& Recycling 83: 202-212.

2. Wang L, Vincent Wang X, Liang G, Váncz J (2014) A cloud-based approach for WEEE remanufacturing. CIRP Annals-Manufacturing Technology 63: 409-412.

3. Ongondo FO, Williams ID, Dietrich J, Carroll C (2013) ICT reuse in socio-economic enterprises. Waste Management 33: 2600-2606.

4. Kissling R, Coughlan D, Fitzpatrick C, Boeni H, Luepschen C, et al. (2013) Success factors and barriers in re-use of electrical and electronic equipment. Resources, Conservation \& Recycling 80: 21-31.

5. AchillasCh, Aidonis D, VlachokostasCh, Karagiannidis A, Moussiopoulos N, et al. (2013) Depth of manual dismantling analysis: A cost-benefit approach. Waste Management 33: 948-956.

6. Gui L, atasu A, Ergun O, Toktay LB (2013) Implementing Extended Producer Responsibility Legislation: A Multi-stakeholder case analysis. Journal of Industrial Ecology 17: 262-276.

7. Dwivedy M, Mittal RK (2012) An investigation into e-waste flows in India. Journal of Cleaner Production 37: 229-242.

8. Solé M, Watson J, Puig R (2012) Proposal of a new model to improve the collection of small WEEE: A pilot project for the recovery and recycling of toys. Waste management \& research 30: 1208-1212.

9. Herat S, Agamuthu P (2012) E-waste: A problem or an opportunity? Review of issues, challenges and solutions in Asian countries. Waste management \& research 30: 1113-1129.

10. Ongondo FO, Williams ID (2011) Mobile phone collection, reuse and recycling in the UK. Waste Management 31: 1307-1315.
11. Townsend TG (2011) Environmental Issues and Management Strategies for Waste Electronic and Electrical Equipment. Journal of the Air \& Waste Management Association 61: 587-610.

12. Rousis K, Moustakas K, Stylianou M, Papadopoulos A, Loizidou M (2011) Management of waste from electrical and electronic equipment in Cyprus- a cases study. Environmental Engineering and Management Journal 10: 703-709.

13. Ongondo FO, Williams ID, Cherrett TJ (2011) How are WEEE doing? A global review of the management of electrical and electronic wastes. Waste Management 31: 714-730.

14. Bereketli I, ErolGenevois M, EsraAlbayrak Y, Ozyol M (2011) WEEE treatment strategies' evaluation using fuzzy LINMAP method. Expert Systems with Applications 38: 71-79.

15. Achillas C, Moussiopoulos N, Karagiannidis A, Vlachokostas C, Banias G (2010) Promoting reuse strategies for electrical/electronic equipment Proceedings of Institution of Civil Engineers. Waste and Resource Management 163: 173-182.

16. Fortin J (2010) The rise of the Ressourceries' network. Techniques Sciences - Methods 9: 40-47.

17. Yu J, Williams E, Ju M, Shao Ch (2010) Managing e-waste in China: Policies, pilot projects and alternative approaches. Resources, Conservation \& Recycling 54: 991-999.

18. Walther G, Steinborn J, Spengler Th, Luger T, Herrmann Ch (2010) Implementation of the WEEE-Directive - economic effects and improvement potentials for reuse and recycling in Germany. International Journal of Advanced Manufacturing Technology 47: 461-474.

19. Geyer R, Blass VD (2010) The economics of cell phone reuse and recycling. International Journal of Advanced Manufacturing Technology 47: 515-525.

20. Papaoikonomou K, Kipouros S, Kungolos A, Somakos L, Aravossis K (2009) Marginalised social groups in contemporary weee management within social enterprises investments: A study in Greece. Waste Management 29: 1754-1759.

21. Roller G, Führ M (2008) Individual Producer Responsibility: A remaining Challenge under the WEEE Directive. Reciel 17:277-283.

22. Aizawa H, Yoshida H, Sakai S-I (2008) Current results and future perspectives for Japanese recycling of home electrical appliances. Resources, Conservation \& Recycling 52: 1399-1410.

23. Yang J, Lu B, Xu Ch (2008) WEEE flow and mitigating measures in China. Waste Management 28: 1589-1597.

24. Rousis K, Moustakas K, Malamis S, Papadopoulos A, Loizidou M (2008) Multi-criteria analysis for the determination of the best WEEE management scenario in Cyprus. Waste Management 28: 1941-1954.

25. Babu BR, Parande AK, Basha CA (2007) Electrical and electronic waste: A global environmental problem. Waste management \& research 25: 307-318.

26. Nicol S, Thompson S (2007) Policy options to reduce consumer waste to zero: comparing product stewardship and extended producer responsibility for refrigerator waste. Waste management \& research 25 227-233.

27. Truttmann N, Rechberger H (2006) Contribution to resource conservation by reuse of electrical and electronic household appliances. Resources, Conservation and Recycling 48: 249-262.

28. Streicher-Porte M, Widmer R, Jain A, Scheidegger R, Kytzia S (2005) Key drivers of the e-waste recycling system: Assessing and modelling e-waste processing in the informal sector in Delhi. Environmental Impact Assessment Review 25: 472-491. 
Citation: Queiruga D, Queiruga-Dios A (2015) The Reuse of Waste Electrical and Electronic Equipment (WEEE). A Bibliometric Analysis. Int J Waste Resour 5: 177. doi:10.4172/2252-5211.1000177

Page 8 of 8

29. Darby L, Obara L (2005) Household recycling behavior and attitudes towards the disposal of small electrical and electronic equipment. Resources, Conservation and Recycling 44: 17-35.

30. Goosey M (2004) End-of-life electronics legislation - an industry perspective. Circuit World 30: 41-45.

31. Hume A, Grimes S, Boyce J (2002) Environmental product attributes in end-of-life management in the UK. Part I: An end-of-life eco-declaration for waste IT and office equipment. International Journal of Environment and Pollution 18: 109-125.

32. Hume A, Grimes S, Boyce J (2002) Environmental product attributes in end-of-life management in the UK. Part II: Problems encountered with informational systems for the management of en-of-life IT and office equipment. International Journal of Environment and Pollution 18: 126-137. 